\title{
Concentração plasmática de cortisol, uréia, cálcio e fósforo em vacas de corte mantidas a pasto suplementadas com levedura de cromo durante a estação de monta
}

\author{
Cortisol, urea, calcium and phosphorus plasma concentration in grazing beef cows supplemented with high \\ chromium yeast during breeding season
}

Eduardo Fabian Aragón Vásquez ${ }^{1,2}$ Alexandra del Pilar Naranjo Herrera ${ }^{1}$

\section{RESUMO}

Foi pesquisada a influência da suplementação com cromo (Cr) sobre a concentração plasmática de cortisol, uréia, cálcio e fósforo em vacas zebu mantidas a pasto e numa situação de estresse calórico durante a estação de monta. Foram utilizadas trinta vacas primíparas com peso entre 380 e $385 \mathrm{~kg}$. Os animais foram divididos em grupos de 15 vacas, formando o tratamento suplementado com $\mathrm{Cr}$ e o tratamento não suplementado (controle). As vacas pastorearam em piquetes formados por Brachiaria brizanta cv. Marandu. A fonte de Cr foi levedura enriquecida ( $1 \mathrm{~g} \mathrm{Cr}$ $\mathrm{kg}^{-1}$ de produto comercial) e foi adicionado à mistura mineral aportando 0,017\% de Cr. Amostras de sangue foram tomadas em três períodos através de venipunção jugular e coletadas em tubos contendo heparina. As amostras de plasma foram analisadas para fósforo, cálcio, uréia e cortisol. Os dados foram analisados como um desenho de blocos ao acaso. $O$ consumo médio diário de mistura mineral foi de 72,92g no grupo suplementado com $\mathrm{Cr}(12,40 \mathrm{mg} \mathrm{Cr} /$ cabeça/dia) $e$ $77,84 \mathrm{~g}$ no grupo controle (0,78mg Cr/cabeça/dia). A concentração plasmática de cortisol, no grupo suplementado com $\mathrm{Cr}$, foi menor que no tratamento controle $\left(2,11 \mathrm{mg} \mathrm{dl}^{-1}\right.$ vs. 3,29 mg dl-1). As concentrações plasmáticas de fósforo

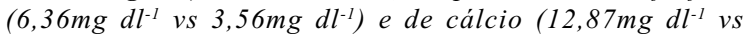
$9,02 \mathrm{mg} \mathrm{dl}^{-1}$ ) foram maiores no grupo suplementado com $\mathrm{Cr}$ durante o primeiro período, mas não existiram diferenças no segundo e terceiro periodos de colheita. Os níveis plasmáticos de uréia $\left(17,13 \mathrm{mg} \mathrm{dl}^{-1}\right.$ vs. $\left.17,70 \mathrm{mg}^{-1}\right)$ não foram diferentes entre os grupos experimentais.

Palavras-chave: cromo, cortisol, uréia, cálcio, fósforo, estresse calórico.

\begin{abstract}
The influence of supplemental chromium (Cr) on plasma cortisol, urea, calcium and phosphorus concentration were investigated in grazing cattle in caloric stress situation during the breeding season. Thirty primiparous zebu cows with 380 to $385 \mathrm{~kg}$ of body weight were assigned to the following treatments: 15 cows fed supplemental $\mathrm{Cr}$ and 15 cows without supplemental Cr (Control). The cows were grazing in Brachiaria brizantha pasture. Chromium was supplied as high-Cr yeast Sacharomices cerevisae $\left(1 \mathrm{gCr} \mathrm{kg}^{-1}\right)$. Chromium was added to mineral premix to provide $0.017 \%$ of supplemental Cr. Blood samples were collected in three periods by jugular venipuncture in heparinized tubes. Plasma was analysed for phosphorus, calcium, urea and cortisol. Data were analysed as a randomised block design. Premix daily consumption was $72.92 \mathrm{~g}$ in the supplemented cow (12.40mg Cr/animal/day) and $77.84 \mathrm{~g}$ premix in the non supplemented cow (0.78mg Cr/animal/day) groups. The concentration of cortisol in $\mathrm{Cr}$ supplemented group was lower than that in control

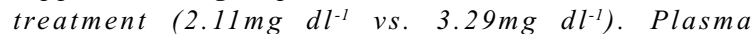
phosphorus $\left(6.36 \mathrm{mg} \mathrm{dl^{-1 }} \mathrm{vs} .3 .56 \mathrm{mg} \mathrm{dl^{-1 } )}\right.$ and calcium

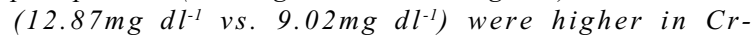
supplemented group in the first period but no differences were found between groups in other periods. There was no difference in urea level (17.13 $\mathrm{mg} \mathrm{dl}^{-1}$ vs $17.70 \mathrm{mg} \mathrm{dl}^{-1}$ ) between supplemented and control group.
\end{abstract}

Key words: chromium, cortisol, urea, calcium, phosphorus, caloric stress.

${ }^{1}$ Medico Veterinário e Zootecnista, Mestre em Zootecnia, Doutorando em Ciência Animal, Escola de Veterinária, Universidade Federal de Minas Gerais (UFMG).

${ }^{2}$ Departamento de Zootecnia, Escola de Veterinária, UFMG, CP 567, Avenida Antonio Carlos, 6627, 30123-970, Belo Horizonte-

MG. E-mail: eduardoaragon@yahoo.com. Autor para correspondência. 


\section{INTRODUÇÃO}

A primeira função do cromo $(\mathrm{Cr})$ no metabolismo, relacionada com o Fator de Tolerância à Glicose (GTF), foi descrita por SCHWARZ \& MERTZ (1959). A partir disto, tem sido demonstrado que o $\mathrm{Cr}$ é essencial na nutrição humana e animal, principalmente sob condições de estresse, sendo considerado como um elemento antiestresse.

Nos últimos anos, têm sido desenvolvidas várias pesquisas em bovinos nesse tema, sendo a grande maioria delas orientadas a novilhos de corte no período pós-desmama (CHANG \& MOWAT, 1992; MOONSIE-SHAGEER \& MOWAT, 1993; MOWAT et al., 1993; BURTON et al., 1994) ou a vacas leiteiras no período próximo ao parto ou no início da lactação (BURTON et al., 1993; SUBIYATNO et al., 1996; YANG et al., 1996). Todos esses trabalhos têm demonstrado que o $\mathrm{Cr}$ pode agir como um moderador da resposta imune e poderia favorecer a resposta produtiva dos animais (ganho de peso ou produção de leite) quando esses são submetidos a situações estressantes, como transporte, comercialização, parto e início da lactação (principalmente em vacas primíparas). Tudo isto pelo fato de o elemento cromo estar estreitamente vinculado ao metabolismo dos carboidratos, proteínas e lipídeos (ANDERSON, 1987).

Em vacas de corte em condições tropicais, os trabalhos são bastante limitados. Por estes antecedentes, o presente trabalho objetivou estudar a influência da suplementação com $\mathrm{Cr}$, na forma de levedura, na concentração plasmática de cortisol, uréia, cálcio e fósforo em vacas zebu mantidas em sistemas a pasto, numa situação estressante produzida pelas altas temperaturas e umidade relativa do ar durante a estação de monta.

\section{MATERIAL E MÉTODOS}

Foram utilizadas 30 vacas Zebu de primeiro parto, com idade média de 30 meses e peso entre 380 e $385 \mathrm{~kg}$. Os animais foram divididos, na hora do parto, em dois grupos: um grupo controle de 15 vacas, o qual não recebeu cromo suplementar, e um grupo experimental, que recebeu $\mathrm{Cr}$ suplementar. As vacas permaneceram com os bezerros durante a estação de monta, período no qual foi desenvolvido o trabalho. Os animais foram mantidos em piquetes formados por Brachiaria brizanta num sistema de pastoreio rotacional com permanência de três dias em cada faixa. $\mathrm{O}$ experimento foi conduzido entre os meses de dezembro de 1998 a fevereiro de 1999. A temperatura e umidade relativa do ar mensuradas, durante o período experimental, são apresentadas na tabela 1 e foram determinadas as zonas de conforto fisiológico segundo o esquema do índice de temperatura e umidade (THI) sugerido por Wiersma (1990), citado por ARMSTRONG(1994).

A fonte de $\mathrm{Cr}$ foi a levedura Sacharomices cerevisae $^{\mathrm{a}}$ (1g Cr $\mathrm{kg}^{-1}$ de produto). O cromo foi adicionado à mistura mineral dos animais suplementados. A composição química do suplemento mineral é detalhada na tabela 2. Os animais receberam o suplemento mineral nos cochos localizados nos piquetes.

Realizaram-se três colheitas de sangue dos animais com intervalos de 30 dias entre colheitas. As amostras foram tomadas pela manhã por meio de punção na veia jugular utilizando-se "vacutainer" com heparina ${ }^{b}$ como anticoagulante. O plasma foi imediatamente obtido por centrifugação a $1000 \times \mathrm{g}$ por 15 minutos à temperatura ambiente. As amostras foram congeladas a $-18^{\circ} \mathrm{C}$ para posteriores análises.

As análises realizadas foram: cortisol $^{\mathrm{c}}$ por radioimunoanálise (RIA) em fase sólida, uréia $^{\mathrm{d}}$, pela metodologia enzimática colorimétrica, cálcio $^{\mathrm{e}}$, pela metodologia colorimétrica de cresolftaleína

Tabela 1 - Temperatura e umidade relativa do ar e índice de temperatura-umidade (THI) durante a estação de monta.

\begin{tabular}{lcccc}
\hline Colheita & $\begin{array}{c}\text { Temperatura } \\
\left({ }^{\circ} \mathrm{C}\right)\end{array}$ & $\begin{array}{c}\text { Umidade relativa } \\
\text { do } \operatorname{Ar}(\%)\end{array}$ & THI & Estresse \\
\hline Primeira & 35,5 & 78 & 92 & Severo \\
Segunda & 31,0 & 70 & 83 & Severo \\
Terceira & 27,5 & 65 & 77 & Moderado \\
\hline
\end{tabular}

Tabela 2 - Composição (\%) química do suplemento mineral

\begin{tabular}{lcc}
\hline Elemento & Suplementado Cr & Controle \\
\hline Cálcio & 13 & 13 \\
Fósforo & 7,5 & 7,5 \\
Enxofre & 1,19 & 1,19 \\
Cobre & 0,09 & 0,09 \\
Zinco & 0,43 & 0,43 \\
Manganês & 0,06 & 0,06 \\
Magnésio & 0,55 & 0,55 \\
Iodo & 0,0094 & 0,0094 \\
Selênio & 0,0018 & 0,0018 \\
Cromo & $\mathbf{0 , 0 1 7}$ & $\mathbf{0 , 0 0 1}$ \\
Cobalto & 0,0072 & 0,0072 \\
Sal comum & 20 & 20 \\
Proteína Bruta & 18,40 & 18,40 \\
Monensina & 0,15 & 0,15 \\
\hline
\end{tabular}


complexona, e fósforo ${ }^{\mathrm{f}}$ por colorimetria com fosfomolibdato (CUNNIF, 1995).

Os dois tratamentos foram definidos como blocos inteiramente ao acaso sendo cada colheita um subbloco. As médias foram comparadas pelo teste de " $\mathrm{t}$ " Student com probabilidade de 5\% (SAMPAIO, 1998).

\section{RESULTADOS}

O consumo médio diário de mistura mineral por animal foi de $72,92 \mathrm{~g}$ para o grupo suplementado com $\mathrm{Cr}$, o que correspondia a $12,40 m g \mathrm{de} \mathrm{Cr} / \mathrm{vaca} / \mathrm{dia}$, e $77,84 \mathrm{~g}$ no grupo controle, equivalente a $0,78 \mathrm{mg}$ de $\mathrm{Cr} /$ vaca/dia. A concentração plasmática de cortisol, uréia, cálcio e fósforo, durante as três colheitas e as médias totais, são apresentados nas tabelas 3 e 4 .

\section{DISCUSSÃO}

Os glicocorticóides são conhecidos inibidores da produção de anticorpos, da fagocitose, da produção de fatores ativadores dos linfócitos e da produção do fatores de crescimento das células T (MUNK et al., 1984; KHANSARI et al., 1990), indicando sua grande influência sobre o sistema imune. Nas condições em que estão sendo submetidos os animais nos sistemas de produção modernos, vêm-se provocando neles diferentes graus de estresse devidos a alterações nutricionais, patológicas, metabólicas e/ou ambientais, causando aumento nos níveis plasmáticos de glicorticóides, principalmente cortisol (ROTH \& KAEBERLE, 1982). Os valores encontrados para cortisol, neste trabalho coincidem com os resultados obtidos por KEGLEY \& SPEAR

Tabela 3 - Concentração plasmática de cortisol, uréia, cálcio e fósforo em vacas primíparas durante a estação de monta, suplementadas ou não com cromo.

\begin{tabular}{|c|c|c|c|c|c|c|}
\hline \multirow{3}{*}{ Indicador } & \multicolumn{6}{|c|}{ Colheita } \\
\hline & \multicolumn{2}{|c|}{ Primeira } & \multicolumn{2}{|c|}{ Segunda } & \multicolumn{2}{|c|}{ Terceira } \\
\hline & $\mathrm{S}$ & $\mathrm{C}$ & $\mathrm{S}$ & $\mathrm{C}$ & S & $\mathrm{C}$ \\
\hline Cortisol $(\mu \mathrm{g} / \mathrm{dl})$ & $1,64^{\mathrm{a}}$ & $3,33^{b}$ & $2,18^{\mathrm{a}}$ & $3,39^{b}$ & $2,52^{\mathrm{a}}$ & $3,16^{b}$ \\
\hline Uréia (mg/dl) & 18,3 & 17,3 & 15,8 & 17,02 & 17,28 & 18,77 \\
\hline Cálcio (mg/dl) & $12,87^{\mathrm{a}}$ & $9,02^{\mathrm{b}}$ & $11,69^{\mathrm{a}}$ & $12,98^{\mathrm{a}}$ & $14,93^{\mathrm{a}}$ & $15,27^{\mathrm{a}}$ \\
\hline Fósforo (mg/dl) & $6,36^{\mathrm{a}}$ & $3,56^{\mathrm{b}}$ & $5,98^{a}$ & $6,51^{\mathrm{a}}$ & $7,63^{a}$ & $8,04^{\mathrm{a}}$ \\
\hline
\end{tabular}

Letras diferentes na mesma linha indicam diferença significativa $(\mathrm{P}<0,05)$.

$\mathrm{S}$ : Valores para o grupo Suplementado com $\mathrm{Cr}$.

$\mathrm{C}$ : Valores para o grupo controle.
Tabela 4 - Valores médios e coeficientes de variação (CV, \%) da concentração plasmática de cortisol, uréia, cálcio e fósforo em vacas primíparas durante a estação de monta.

\begin{tabular}{lccc}
\hline \multirow{2}{*}{ INDICADOR } & \multicolumn{2}{c}{ VALOR MÉDIO } & CV $(\%)$ \\
\cline { 2 - 4 } & Suplementado & Controle & Médio \\
\hline Cortisol $(\mu \mathrm{g} / \mathrm{dl})$ & $2,11^{\mathrm{a}}$ & $3,29^{\mathrm{b}}$ & 31,6 \\
Uréia $(\mathrm{mg} / \mathrm{dl})$ & 17,13 & 17,70 & 29,3 \\
Cálcio $(\mathrm{mg} / \mathrm{dl})$ & 13,16 & 11,75 & 19,2 \\
Fósforo $(\mathrm{mg} / \mathrm{dl})$ & 6,65 & 6,03 & 28,5 \\
\hline
\end{tabular}

Letras diferentes na mesma linha indicam diferença significativa $(\mathrm{P}<0,05)$.

$\mathrm{CV}$ : coeficiente de variação.

(1995), CHANG \& MOWAT (1992), MOONSIESHAGEER \& MOWAT (1993), e MOWAT et al. (1993), nos quais a concentração de cortisol foi significativamente menor nos animais que receberam $\mathrm{Cr}$, embora os autores supracitados tenham utilizado como fatores estressantes o transporte e a comercialização dos animais após terem sido desmamados. Já no presente trabalho, o fator estressante foi a condição climática (temperatura e umidade elevadas), mostrando que o cromo poderia agir como um elemento atenuador dos efeitos desfavoráveis provocados pelo estresse térmico, confirmando a sugestão de MERTZ (1974) de considerar o cromo como um elemento antiestresse.

ORR et al. (1990) demonstraram que a concentração plasmática de fósforo, cálcio e outros elementos minerais diminui significativamente em animais estressados. Os resultados deste trabalho (Tabelas 3 e 4) indicaram que, quando os animais foram submetidos a estresse, provocado pelo clima cálido e úmido e o manejo, durante a estação de monta (detecção de cio, inseminações), os valores de fósforo e cálcio foram menores no grupo controle somente durante o primeiro período de colheita, quando a temperatura ambiente e a umidade relativa do ar foram mais elevadas (Tabela 1), sendo que, inclusive no caso do fósforo, o valor do grupo controle foi menor que o nível crítico sugerido por McDOWELL (1992). Já na segunda e terceira colheitas, assim como na média geral, não foi observada diferença significativa. Isto sugere que a resposta à suplementação com cromo é observada, quando o agente estressante exerce maior influência sobre o ambiente no qual estão sendo manejados os animais. No terceiro período, os valores de cálcio, para os dois grupos está pouco acima do valor 
normal de 8 a $14 \mathrm{mg} 100 \mathrm{ml}^{-1}$ sugerido por McDOWELL (1992).

O nível de nitrogênio na dieta, alto ou baixo, parece estar relacionado com problemas reprodutivos nos rebanhos. O equilíbrio entre energia e proteína é determinante no início da atividade ovariana e na involução uterina durante o pós-parto (WATHES, 1998). Conseqüentemente, alterações nesse equilíbrio podem chegar a provocar atraso no início da atividade ovariana no pós-parto e queda nas taxas de fertilidade. Valores elevados de uréia plasmática podem inclusive favorecer a difusão da uréia para os órgãos reprodutivos e a mucosa vaginal, alterando o ambiente uterino e causando mortalidade embrionária, ou impedir a fecundação através de um efeito espermicida (HAMMON et al., 2000), o que refletiria no aparecimento de cios não detectáveis e ciclos estrais irregulares. Não existiu diferença significativa nos valores de uréia plasmática (Tabelas 3 e 4) entre os animais do grupo suplementado com $\mathrm{Cr}$ e as vacas do grupo controle. Como foi sugerido por ANDERSON (1987), o cromo estaria relacionado com o metabolismo protéico e, sendo que a uréia sangüínea é um bom indicador do perfil metabólico protéico (GONZALEZ et al., 2000), os resultados deste trabalho mostraram que, sob essas condições experimentais, não houve efeito do $\mathrm{Cr}$.

\section{CONCLUSÃO}

Os resultados sugerem que a suplementação de $\mathrm{Cr}$, na forma de levedura, pode ajudar a controlar os efeitos negativos causados pelo estresse térmico, principalmente quando o grau de estresse apresenta maior influência. São necessários mais trabalhos sob condições tropicais para determinar se a suplementação com $\mathrm{Cr}$ pode manifestar seus benefícios sobre os parâmetros reprodutivos e produtivos, permitindo desta forma favorecer a viabilidade econômica do sistema.

\section{FONTES DE AQUISIÇÃO}

aBIO-CHROMEâ, Alltech Biotechnology Center

becton Dikinson Vacutainer Systems

${ }^{\mathrm{C}}$ Kit Coat-A-Count DPC ${ }^{2} \mathrm{O}$

dAnalisa Diagnostica Catálogo 227

eAnalisa Diagnóstica Catálogo 248

${ }^{\mathrm{f}}$ Analisa Diagnóstica Catálogo 242

\section{REFERÊNCIAS BIBLIOGRÁFICAS}

ANDERSON, R.A. Chromium. In: MERTZ, W. Trace elements in human and animal nutrition. New York : Academic, 1987. p.225-244.
ARMSTRONG, D.V. Heat stress interaction with shade and cooling. Journal Dairy Science, Urbana, v.77, n.8, p.20442050, 1994.

BURTON, J.L.; MALLARD, B.A.; MOWAT, D.N. Effects of supplemental chromium on immune resposnse of periparturiente and early lactation dairy cows. Journal Animal Science, Urbana, v.71, n.8, p.1532-1539, 1993.

BURTON, J.L.; MALLARD, B.A., MOWAT, D.N. Effects of supplemental chromium on antibody resposnses of newly weaned feedlot calves to immunisation with infectous bovine rhinotracheitis and parainfluenza 3 virus. Canadian Journal Veterinary Research, Guelph, v.58, n.1, p.148-151, 1994.

CHANG, X.; MOWAT, D.N. Supplemental chromium for stressed and growing feeder calves. Journal Animal Science, Urbana, v.70, n.3, p.559-565, 1992.

CUNNIF, P. Official methods of analysis of AOAC International. 16.ed. Arlington : AOAC International, 1995. 2v.

GONZALEZ, F.H.D. et al. Perfil metabólico em ruminantes: seu uso em nutrição e doenças nutricionais. Porto Alegre : Universidade Federal do Rio Grande do Sul, 2000. p.106.

HAMMON, D.S.; WANG, S.; HOLYOAK, G.R. Ammonia concentration in boivne follicular fluid and its effect during in vitro maturation on subsequent embryon development. Animal Reproduction Science, New York, v.58, n.1, p.18,2000 .

KEGLEY, E.B.; SPEARS, L.W. Immune responses, glucose metabolism and performance of stressed feeder calves fed inorganic and organic chromium. Journal Animal Science, Urbana, v.73, n.11, p.2721-2726, 1995.

KHANSARI, D.N.; MURGO, A.J., FAITH, R.E. Effects of stress on the immune system. Immunology Today, London, v.11, n.2, p.170-175, 1990 .

McDOWELL, L.R. Minerals in animal and human nutrition. New York: Academic, 1992. 370p.

MERTZ, W. Chromium as dietary essential for man. In: HOESKTRA, W.G. Trace element metabolism in animals-2. Baltimore : University Park, 1974. p.123-138.

MOONSIE-SHAGEER, S.; MOWAT, D.N. Effect of level of supplemental chromium on performance, serum constituents, and immune status of stressed feeder calves. Journal Animal Science, Urbana, v.71, n.1, p.232-238, 1993.

MOWAT, D. N.; CHANG, X; YANG, W.Z. Chelated chromium for stressed feeder calves. Canadian Journal Animal Science, Guelph, v.73, n.1, p.49-55, 1993

MUNCK, A.; GUYRE, P.; HOLBROOK, N. Physiological functions of glucocorticoids in stress and their relation to pharmacological actions. Endocrinology Veterinary, New York, v.5, n.1, p.25-44, 1984.

ORR, C. L. et al. Serum copper, zinc, calcium and phosphorus concentrations of calves stressed by bovine respiratory disease and infectious bovine rhinotracheitis. Journal Animal Science, Urbana, v.68, n.12, p.2893-2900, 1990. 
ROTH, J.A.; KAEBERLE, M.L. Effect of glucocorticoids on the bovine immune system. Journal American Veterinary Medical Association, v.180, n.5, p.894-901, 1982 .

SAMPAIO, I.B.M. Estatística aplicada à experimentação animal. Belo Horizonte : Fundação de Ensino e Pesquisa em Medicina Veterinária e Zootecnia, 1998. 221p.

SCHWARZ, K.; MERTZ, W. Chromium (III) and the glucose tolerance factor. Archives Biochemical Biophysics, Berlin, v.85, n.3, p.292-295, 1959.
SUBIYATNO, A.; MOWAT, D.N.; YANG, W.Z. Metabolite and hormonal responses to glucose or propionate infusions in periparturiente dairy cows supplemented with chromium. Journal Dairy Science, Urbana, v.79, n.6, p.1436-1445, 1996.

WATHES, D.C. Nutritional effects on reproductive performance in dairy cows. Cattle Practice, Masey, v.6, p.371-377, 1998

YANG, W. Z. et al. Effects of chromium supplementation on early lactation performance of Holstein cows. Canadian

Journal Animal Science, v.76, n.2, p.221-230, 1996 